\author{
Proceedings of the $9^{\text {th }}$ International Conference on Applied Informatics \\ Eger, Hungary, January 29-February 1, 2014. Vol. 1. pp. 285-294 \\ doi: 10.14794/ICAI.9.2014.1.285
}

\title{
Strategy of guessing exercises - Variations of drawing trees
}

\author{
Viktória Heizlerné Bakonyi, László Zsakó \\ ELTE IK \\ hbv@inf.elte.hu \\ zsako@caesar.elte.hu
}

\begin{abstract}
In informatics we often have to tempt students to solve different problems. This is required partly during practice and partly during tests (moreover this is especially important in the preparation for informatics competitions). We give two different methods of creating different but still commensurate exercises: one of them is to start from a base problem, and make some changes on it in small steps; the other way is to look for variations of the base task solution. ${ }^{1}[11]$
\end{abstract}

Keywords: Logo tree, strategy, variation, base problem

$M S C:$ 97Q30

Let us review this topic through a Logo drawing problem. These exercises thanks to the including recursivity - make it possible to use a third method as well; the combination of the first two methods. Logo is suitable to take notice of special effects besides classical parameterizing as well for making new exercises.

In this article we are not aiming to review Logo language, or to write about fractals (L-systems) standing behind trees, neither to create nor use complicate mathematical formulas...

Publications about Logo-trees mainly present the base problem with some variations, but they are not dealing with systematical teaching steps, neither gives a helping hand to teachers how to create new exercise-variations.

One nice exception is Andrzej Walat's paper [3], in which he shows variations of fractals (addition of a scale factor, variations of Sierpiński pentagons, why not

\footnotetext{
${ }^{1}$ There is a third case as well, in which the tasks are differentiating from each other that they are vesting in „new gowns”. In teaching process (and it is true for the competitions as well) we do not use dull exercises, rather guess some „tales” around them. The student's first task is to specificate and determine the problem properly. That is why, it is imaginable, that we guess a lot of „tales" for the same problem, but students reaching the abstract exercise; they have to solve the same (e.g. roots, bushes, algae instead of trees). But this case is not the theme of this paper.
} 
add a bit of randomness, exploiting rotations of the square, cumulated RS, seeing the simple and cumulated RS shapes together, adding reflection to rotation).

In this paper we aim to show, how can to create newer and newer exercises proceeding from a base problem by drawing a tree.

The exercises proceeding from the program of the base problem: [12]

- only the parameters are changing (angles, lengths)

- the count of calling are changing (the count of branches are not 2)

- new features, depending on levels: width, colour (the last branch differs, there is a continuous changing), the count of branches

The exercises proceeding from the result of the base problem: [1]

- not growing, but thickening trees

- the trunk or part of it is a tree too

- the base element are different (e.g. pinewood, cactus, trees of special trunks)

Exercises combining the two methods:

- two different types of tree are calling each other (the count of branches, the angle of branches, the length of branches are different), the left and right tree are different

- we draw the left and right side of branches separate

Exercises influenced by external effects:

- changes directed by heading or measure, heading directed with curve lines, directed by position (e.g. do not reach under the root)

- the tree is not symmetric (parameterized with a list, given the structure )

- random trees (random growing, random length of branches, random ... )

\section{Exercises proceeding from the program of the base problem}

The essence of the method is, to get a base exercise, and then change the solution of it step by step to get new exercises. The created exercises can be on the same level of difficulty with the original one, but they can belong to different ones as well.

These exercises differ from each other by types, so that general disciples cannot be given, they can be examined only by examples. 
The base exercise: A tree has got an : 1 long length trunk, at the end of it two new trees are growing out symmetrically, in angle of 120 degrees compared to the original tree. From the bottom of the tree there are $: \mathrm{n}$ steps, the length of new trees, growing from the end of the original one are the two third of it.

The Logo solution:
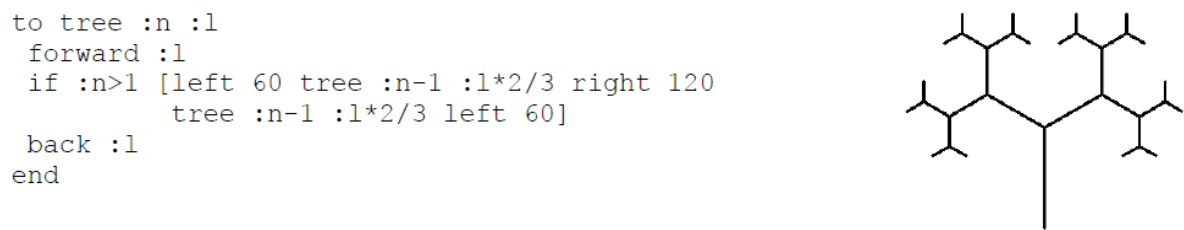

Variations: [8]

variation 1: the proportion of left and right length of trunks should be different! variation 2: change the angle of branches! variation 3: change the count of branches! variation 4: change the width of branches! [2] variation 5: change the colour of branches: the last should be green, the others are brown!

variation 6: change the colour of branches, they should be lighter and lighter red towards the younger ones!

variation \%: change the count of steps from trunk to leaves!

variation 8: let the count of branches different on different levels!<smiles>CC(C)C(C)C(C(C)C)C(C(C)C)C(C)C</smiles>

variation 1<smiles>CC(C)C(C(C)C)C(C(C)C)C(C(C(C)C)C(C)C)C(C(C)C)C(C(C)C)C(C)C</smiles>

variation 5

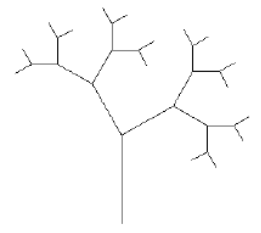

variation 2

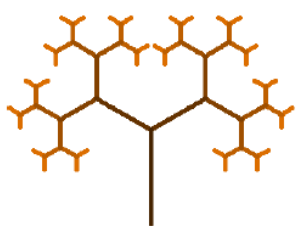

variation 6

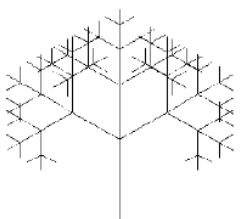

variation 3

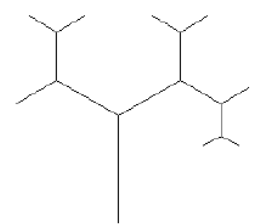

variation 7

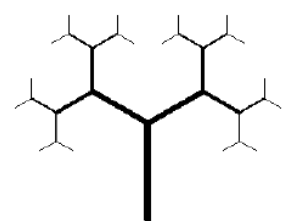

variation 4

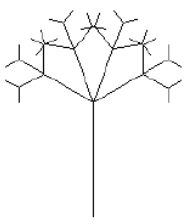

variation 8

The solutions can be downloaded from http://prognyelvokt.elte.hu/ /downloads/ICAI/Logo-Trees_Solutions.pdf [13]

Of course, these 8 variations can be combined anyway, so a tree can be drawn which branches into three, of which left branch is shorter and tends upwards the width of them are smaller. 


\section{Problem sheet proceeding from the result of the base problem}

Instead of proceeding of the program code of the base problem, we can use the result of it, which means its picture now. This method is rather rare in the world of programming, usually it is possible if the result is adequate complex (mainly at graphical result, but it is not necessary. As the result is the exercise itself, so this method belongs to that group where we have to change the task. At first try let us grow new branches from some part of the trunk as well! [5,7]

variation 9: One part of the trunk remains constant, let the other one be a new branch! From the bottom of the branch a new branch grows to the left, at the upper end of it grows another one into the right direction.

variation 10: The trunk is now two branches! From the bottom branch a new branch grows to the left, from the upper branch two new branches are growing one to the right and one up-wards.

variation 11: The tree is created from 5 branches, from which 3 are along the trunk and two of them are brunching from it.

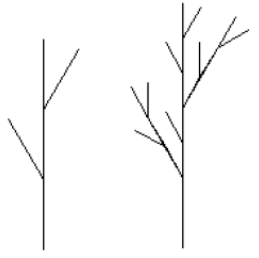

variation 9
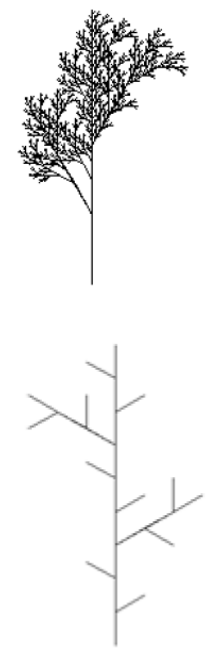

variation 11
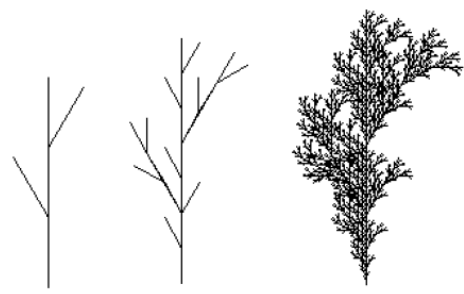

variation 10

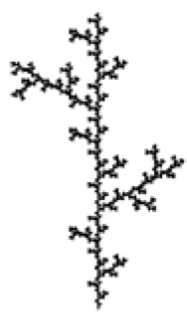


In the above mentioned solutions we unhinge bold that part, which was placed instead of drawing out the base trunk:

The solutions can be downloaded from [13]

variation 12: The trunk of tree is a rhombus. The trunk's bottom sideward part a new branch grows into each direction, and two branches from the top of it.

variation 13: The trunk of the tree is a rectangle with :w width. A left-side branch bevels 30 degrees, the right-side branch bevels 60 degrees to the trunk.

variation 14: The trunk of the tree is a rectangle with :w width. Both of branches bevel to the trunk 60 degrees.

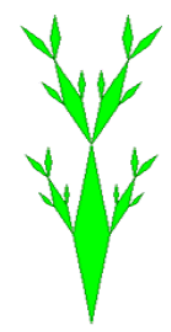

variation 12

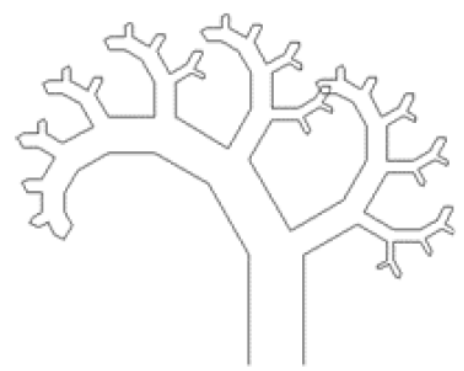

variation 13

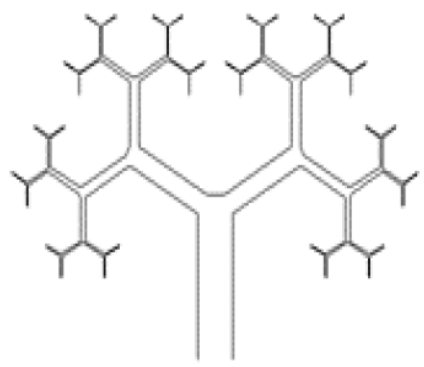

variation 14

At the example of cactus, the newest thing - in addition to the painted inner is that new branches are growing from its sideward.

The featuring of the two trees with wider trunks are - together with cactus that we do not come back on the same line after drawing branches than we have gone forward before. That is why at these trees a new parameter, the width of the tree is appearing.

The solutions for other variations can be downloaded from [13]

\section{Exercises combining the two methods}

In solutions which contain recursion, we can use indirect recursion. Several times we have to draw a tree, which has different features on different levels. In these cases we write two or more tree-drawing procedures, which call each other. [1]

variation 15: alternating 2 or 3 branchings!

variation 16: alternating 120 and 90 degrees on the tree branches bevel!

variation 1\%: left and right trees are different!

variation 18: the tree is created from left- and right-tree! 


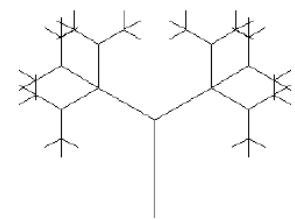

variation 15

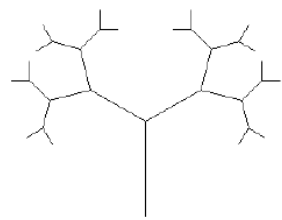

variation 16

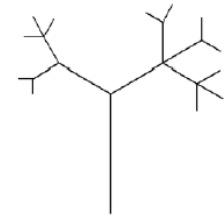

variation 17

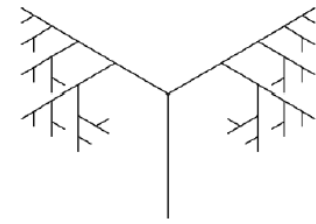

variation 18

Let us see, which program variation suits to different graphs (in procedures calling each other the changings are highlighted by bold)!

The solutions can be downloaded from [13]

Here there are some pictures of pinewood without solution, where the base element was changed to a part of pine:
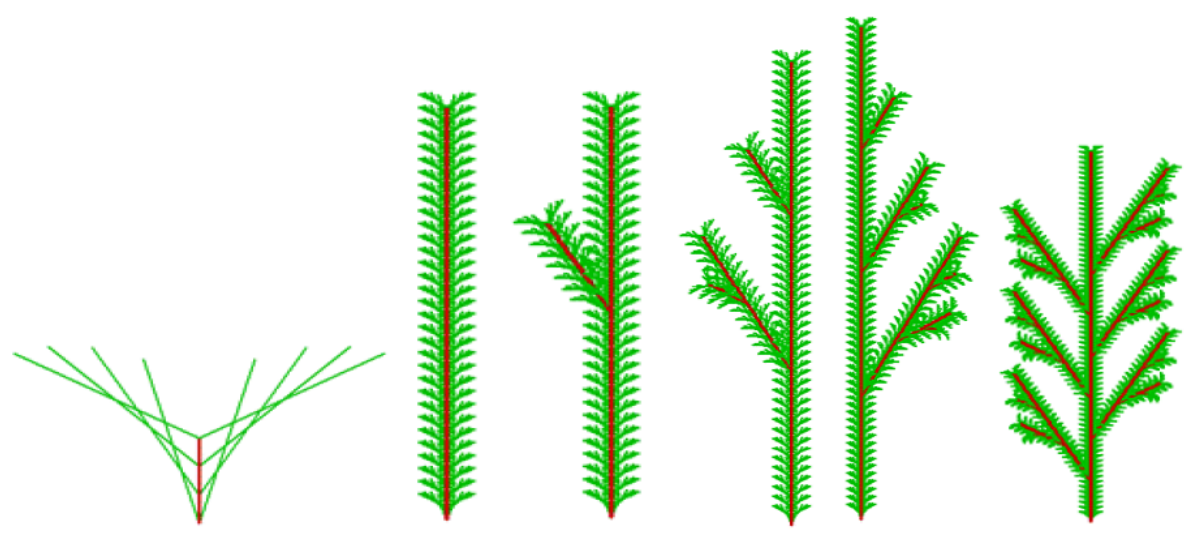

\section{Exercises influenced by external effects}

In the next three variations the effect depends on the value of parameters (from level or length).

variation 19: Fruit trees are pruned in a given year so that the middle of the tree is thinned, in order to get a caldron into which the sun shines. Both sides of the tree branches towards the centre are cut off.

variation 20: In given years tree grows 3 branches, in other years only 2 . The length of branches is the half of the length of the trunk. If there is a middle branch, the length of it is the three quarter of the trunk's length. The colour of the trunk is brown [100 50 50] RGB colour, the width is the (:year). Trending upwards the brown colour is lightening year by year, it means the RGB code colour grows by $\left[\begin{array}{lll}2 & 10 & 0\end{array}\right]$. The width of branches is decreasing by one yearly.

variation 21: The length of the trunk is :1, at the end of each branches there a new branch grows to the left, with the length of :left*:1, and grows to the right with the length of :right*:1 - but only in that case if the length is more than $: \mathrm{k} ![10]$ 


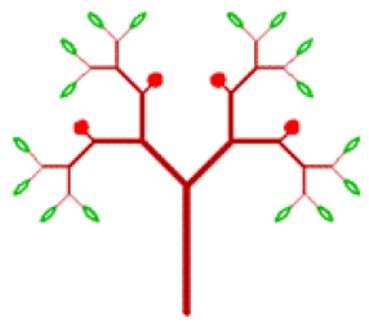

19. variation

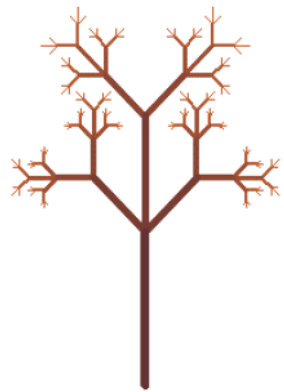

20. variation

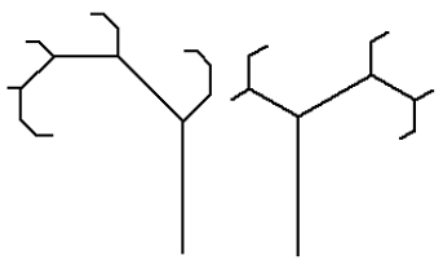

21. variation

The solutions can be downloaded from [13]

In this two new variations, the tree depends on the heading of the turtle.

variation 22: Branches bending to the left to upright curves at the middle 15 degrees to the left, others bending to the right to upright curves to the right by 15 degrees! variation 23: Branches blending to the left to upright at their middle are 30 degrees arcs to the left, the right branches are 30 degrees arcs to the right!

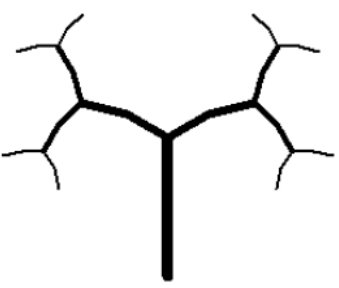

variation 22

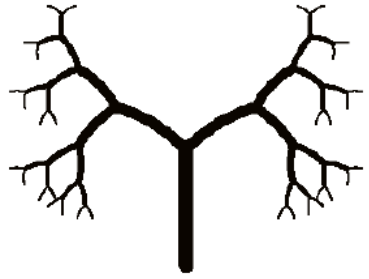

variation 23 with 2 and then with 3 branches

The solutions can be downloaded from [13]

In this group the trees grow randomly.

variation 24: It depends on random, whether a new branch is growing to the left or to the right.

variation 25: The length of left and right branches are depend on random. ${ }^{2}$

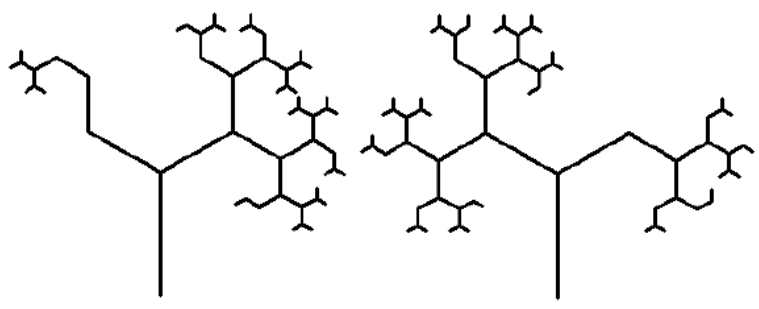

24. variation

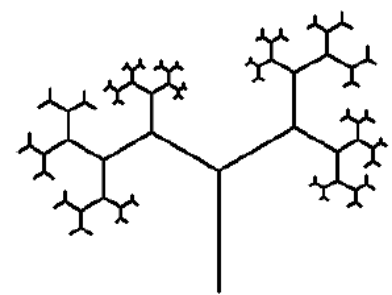

25. variation

\footnotetext{
${ }^{2}$ The count of branches, the bending of them, the width of tree can all be random, ...
} 
The solutions for other variations can be downloaded from [13]

In the last group the growing of trees or the position of mistletoes (fruits, flowers e.g.) are given by a list.

variation 26: The length of left and right branch of the tree are given by a list parameter. The list contains three elements: first the list describing the left parttree, the length of trunk and at last the list describing right part-tree. ( The [[[10]50]100[[40]70[20]]] list describes the 2. tree.)

variation 2\%: The count of branches are given by the list parameter. The first element of the list is the count of branches on the given place, which is followed by part-lists describing the branches. The [2 [3][2 [2]]] list describes the 2. tree.

variation 28: The position of mistletoes living on trees are given by the list parameter. In the list there is a ( . ), where a mistletoe is situated. (The [[[.][.]].[.[.]]] list describes 2. tree.)

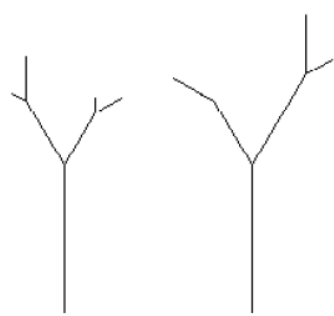

variation 26

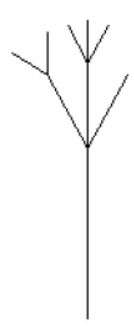

variation 27
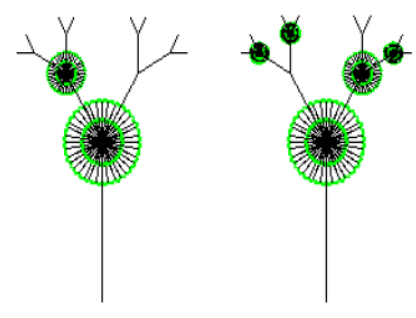

variation 28

The solutions can be downloaded from [13]

Outlook: Let us rotate the trees! If we rotate them several times around their root, they behave like a bush, but it is more interesting if we rotate them completely. This case we get quite spe-cial figures, in which it is hard to explore a tree.
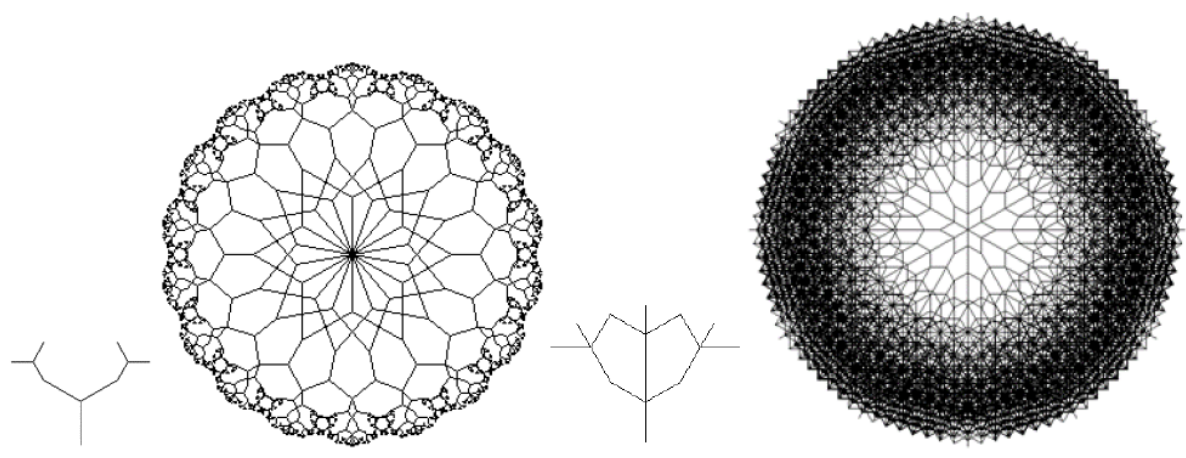


\section{Summary}

Diversifying the exercises are useful from the point of view of the person who guesses a new task and also for who is solving them - as Pólya, György and Lénárd, Ferenc wrote:

„To ring the changes on a problem is very important. There are several reasons of it. Our ad-vancement in problem solving from a point of view stands for how we can mobilize and or-ganize our once formerly gained knowledge. We should wake up some afterimage and we should work them into the task. To ring the changes on a problem helps us to be successful in it. How? Process of remembering is basing on some "contact effect", "association"... During the variation of a task by raising new point of views, we open new contacts, contact points, new possibilities of associations for the important elements of the given problem." [6]

„Solving different problems, tasks variations make possible to get to know these problems and tasks more exact. Without this we cannot find the possibilities by which we can get the result on the way towards the solution." [4]

We can state that each of the method was suitable for creating new tasks. The modification of task in the first group caused only smaller changes in algorithms. The program modification in the second group caused significant changes in result, in tasks. [8]). The combination of the above mentioned two methods can mean some difficulties rather for the students - especially they have to recognize the two algorithm-element from a graph. Drawing trees depending on other effects often need only some idea from the task-guessing person, but can cause serious difficulties for problem-solver.

Combining these methods - though each of them cannot combine to every one we can create several thousands of tasks proceeding from a base task. And now we have not mentioned that we can decorate the trees with fruits, flowers and leaves.

\section{References}

[1] Heizlerné Bakonyi Viktória - Zsakó László: Logo versenyfeladatok tára (2003-2007). Neumann János Számítógép-tudományi Társaság, Budapest, 2003.

[2] Guy M. Haas: jLogo Programming. http://www.bfoit.org/itp/Recursion.html

[3] Izabella Foltynowicz, Andrzej Walat: Fractal Variations. Eurologo 2005, Warsaw, $33-42$

[4] Lénárd Ferenc: A gondolkodás hétköznapjai. Akadémiai Kiadó, 1982.

[5] Gabriela Ochoa: An Introduction to Lindenmayer Systems. The University of Sussex. http://www.biologie.uni-hamburg.de/b-online/e28_3/lsys.html

[6] George Pólya: How to solve it, A new aspect of mathematical method. Princeton Univer-sity Press, 1945.

[7] Christoph Traxler: L-Systems. TU Vienna, http://www.cg.tuwien.ac.at/courses/ Fraktale/PDF/fractals8.pdf

[8] Szentpéteriné Király Tünde: Comenius Logo teknőcgrafika. Kossuth Kiadó, 2000. 
[9] Turcsányiné Szabó Márta - Zsakó László: Comenius Logo gyakorlatok. Kossuth Kiadó, 1997.

[10] Alexandra Yudina: Research projects in Logo for high school students (ages 14-16). Eu-rologo 1997.

[11] Zsakó László: Variations for Spanning Trees. Annales Mathematicae et Informaticae 33, 151-165, Eger, 2006.

[12] Zsakó László: Logo versenyfeladatok tára (1998-2002). Neumann János Számítógéptudományi Társaság, Budapest, 2003.

[13] Solutions http://prognyelvokt.elte.hu/downloads/ICAI/Logo-Trees_ Solutions.pdf 